\title{
Calidad del agua y de la leche en sistemas de ordeño manual de la Sierra Norte del Ecuador
}

\author{
Quality of water and milk in manual milking systems in the Northern \\ Sierra of Ecuador
}

Rocío Contero $^{1,3}$, Charles Cachipuendo ${ }^{2}$

\section{Resumen}

\begin{abstract}
El objetivo del estudio fue determinar la calidad del agua utilizada durante el ordeño manual y su influencia en la calidad microbiológica de la leche. Se trabajó con 63 productores de ganado bovino de comunidades localizadas en Cayambe y Pedro Moncayo en la región Sierra Norte del Ecuador. Las muestras fueron colectadas en las unidades productivas donde realizan el ordeño, en las cuales el $98 \%$ no disponía de agua potable. La población fue categorizada en dos grupos: los que utilizan agua potable, transportada en recipientes (G1) y los que utilizan agua colectada de otras fuentes (lluvia o riego) (G2). G1 presentó agua y leche de calidad aceptable: coliformes totales $<50 \mathrm{NMP} / 100 \mathrm{ml}$; ausencia de coliformes fecales y CBT $<200 \times 10^{3} \mathrm{UFC} / \mathrm{ml}$, en tanto que las muestras de agua y leche de G2 presentaron coliformes totales superando los límites permisibles, presencia de coliformes fecales (29\%) y CBT $>900 \times 10^{3} \mathrm{UFC} / \mathrm{ml}$. En ambos grupos, el análisis en superficie de mesófilos aerobios en los tarros colectores mostró una limpieza inapropiada $\left(>400 \mathrm{UFC} / \mathrm{cm}^{2}\right)$. Se concluye que la calidad del agua utilizada en el ordeño es uno de los factores que incide en la calidad microbiológica de la leche.
\end{abstract}

Palabras clave: ordeño manual, calidad de agua, calidad de leche, producción de leche, Ecuador

${ }^{1}$ Grupo de Investigación de la Leche, Universidad Politécnica Salesiana, Quito, Ecuador

${ }^{2}$ Linea de Investigación en Gestión Sostenible del Agua y del Suelo, Universidad Politécnica Salesiana, Quito, Ecuador

${ }^{3}$ E-mail: rcontero@ups.edu.ec

Recibido: 4 de enero de 2021

Aceptado para publicación: 30 de junio de 2021

Publicado: 24 de agosto de 2021

CLos autores. Este artículo es publicado por la Rev Inv Vet Perú de la Facultad de Medicina Veterinaria, Universidad Nacional Mayor de San Marcos. Este es un artículo de acceso abierto, distribuido bajo los términos de la licencia Creative Commons Atribución 4.0 Internacional (CC BY 4.0) [https:// creativecommons.org/licenses/by/4.0/deed.es] que permite el uso, distribución y reproducción en cualquier medio, siempre que la obra original sea debidamente citada de su fuente original 
The aim of this study was to determine the quality of the water used during manual milking and its influence on the microbiological quality of the milk. In total 63 cattle producers from communities located in Cayambe and Pedro Moncayo in the Sierra Norte region of Ecuador were included in the study. The samples were collected in the productive units where they perform the milking, in which $98 \%$ did not have drinking water. The population was categorized into two groups: those that use drinking water, transported in containers (G1) and those that use water collected from other sources (rain or irrigation) (G2) for the milking process. G1 presented water and milk of acceptable quality: total coliforms $<50 \mathrm{MPN} / 100 \mathrm{ml}$; absence of faecal coliforms and $\mathrm{CBT}<200 \times 10^{3} \mathrm{CFU} / \mathrm{ml}$, while the water and milk samples from $\mathrm{G} 2$ showed total coliforms exceeding the permissible limits, presence of faecal coliforms (29\%) and CBT $>900 \times 10^{3} \mathrm{CFU} / \mathrm{ml}$. In both groups, the surface analysis of aerobic mesophiles in the collection jars showed inappropriate cleaning $\left(>400 \mathrm{CFU} / \mathrm{cm}^{2}\right)$. These findings indicated that the quality of the water used is one factor that affect the microbiological quality of the milk.

Key words: hand milking, water quality, milk quality, milk production, Ecuador

\section{INTRODUCCIÓN}

Las proyecciones de la Organización para la Cooperación y el Desarrollo Económico (OCDE) indican que las demandas de agua dulce a nivel mundial se incrementarán un 55\% para el año 2050 , de allí que la innovación y la tecnología en las actividades agropecuarias deben estar asociadas con la evolución de prácticas que reduzcan el consumo y cuidado de las fuentes de agua (OECD, 2016). El agua utilizada en la producción agrícola y pecuaria en países como Ecuador, Bolivia y Colombia es usualmente agua de riego (Gallegos y Medina, 2019; Henao-Herreño et al., 2017; Perez-Mercado et al., 2018).

En Ecuador, el 58.8\% de la producción total de leche bovina provine de pequeños productores con menos de 5 ha (Vinueza, 2015), en los cuales predomina el sistema de ordeño manual $(>60 \%)$ sobre el ordeño mecánico
(Guamán et al., 2017; Hidalgo, 2010). Por otra parte, la disponibilidad de agua es vital para la producción de leche (Guerra et al., 2011; Ramírez-Rivera et al., 2019); sin embargo, las principales fuentes de agua para la producción agropecuaria provienen de canales abiertos susceptibles a la contaminación que pueden comprometer la calidad de los productos agrícolas, así como la salud de animales y consumidores (Henao-Herreño et al., 2017; Jansen et al., 2019; Poats et al., 2001).

La leche secretada por la glándula mamaria de vacas sanas y bien alimentadas es libre de contaminación bacteriana, pero su condición puede cambiar durante el ordeño, almacenamiento y transporte (Cortezi, 2014; Carloni et al., 2016). Diversos estudios han demostrado que la calidad del agua puede comprometer la salud de la glándula mamaria por la transmisión de microrganismos patógenos durante el ordeño (Amaral et al., 2004; Belage et al., 2017). La calidad del 
agua en la cadena alimenticia es evaluada a través de indicadores microbiológicos (Silva et al., 2010). La legislación ecuatoriana limita los valores microbiológicos para coliformes totales a $<50 \mathrm{NMP} / 100 \mathrm{ml}$ y ausencia de coliformes fecales (INEN, 2014).

El conteo de bacterias totales (CBT) es el método más utilizado por las industrias procesadoras (Cassoli et al., 2007). Conteos altos de bacterias pueden ser alertas de deficiencias en la higiene en áreas de producción y de procesamiento, así como fallas en el control de temperatura de transporte y almacenamiento (Carloni et al., 2016; Cortinhas et al., 2018). Los alimentos que provocan con más frecuencia brotes e infecciones en las personas son aquellos de origen animal (Jansen et al., 2019). Los estándares para CBT indican valores máximos de $100 \times 10^{3}$ $\mathrm{UFC} / \mathrm{ml}$ de acuerdo con el reglamento de la Comunidad Europea (CE) N. ${ }^{\circ} 1662 / 2006$ y de $300 \times 10^{3} \mathrm{UFC} / \mathrm{ml}$ para Brasil (Botaro et al., 2013; Bruzaroski et al., 2017). En Ecuador, a partir de 2013 se limitó un máximo permisible de $300 \times 10^{3} \mathrm{UFC} / \mathrm{ml}$ según el Acuerdo Ministerial 394 para el pago por litro de leche en finca al productor (MAGAP, 2013).

El conteo de mesófilos aerobios es útil para obtener información de la higiene en la manipulación de alimentos. Se ha valorado la calidad de la limpieza en superficies inertes como utensilios de cocina, dispensadores y tablas de cortar, entre otras, así como en superficies vivas (Caro-Hernández y Tobar, 2019). En las etapas de producción y obtención de la leche hay trabajos realizados en pezoneras de ordeño, tanques de enfriamiento y manos de ordeñadores (Cortezi, 2014; Contero, 2018); sin embargo, es escasa la información en el Ecuador sobre la limpieza en la superficie de tarros colectores de leche usados en el ordeño. Ante esto, el objetivo del presente trabajo fue determinar la calidad del agua utilizada por parte de pequeños productores de leche y su incidencia en la calidad microbiológica de la leche y limpieza de los tarros colectores utilizados durante el ordeño manual.

\section{Materiales y MéTodos}

\section{Características del Área y Productores}

El estudio se realizó en los Cantones de Cayambe y Pedro Moncayo $\left(0^{\circ} 032\right.$ N7 $78^{\circ} 103$ O), ubicados al noreste de la provincia de Pichincha, Ecuador (Figura 1). La zona produce el $15 \%$ de la producción nacional de leche (Guamán et al., 2017; INEC, 2019). El agua disponible en el sector proviene de los páramos y deshielos del nevado Cayambe que forman canales de riego que pertenece a la subcuenca del río Pisque. La administración y distribución de concesiones de caudales se encuentra a cargo de las mismas comunidades locales a través de las Juntas de Agua Potable y de Riego (Poats et al., 2001). Los suelos son de origen volcánico caracterizados por su alto contenido de materia orgánica que favorece la estabilidad, estructura y fertilidad del suelo (Urresta et al., 2017).

Se trabajó con 63 productores de leche organizados que colectaban el producto para comercializarlo a una empresa procesadora que paga \$ 0.40 USD por litro. Los controles de calidad eran realizados por la empresa (previa la entrega) y en caso de no cumplirlos, la leche era rechazada y comercializada a un precio más bajo en el mercado informal. Los productores mantienen sus viviendas en los centros poblados con superficies no mayores a 1 ha y con cultivos destinados a la subsistencia diaria (hortalizas, papas, maíz) y en las zonas más altas (>2800 msnm) disponen de la Unidad Productiva Agropecuaria (UPA) con mayor superficie ( $>2$ ha), dedicada al pastoreo del ganado en la cual disponen de agua de riego pero no de agua potable.

\section{Muestras y Análisis Microbiológico}

En la etapa de socialización del proyecto fueron identificados dos grupos de productores: aquellos que utilizaban agua potable (G1) durante el ordeño y los que utilizaban agua de otras fuentes como de lluvia o de riego almacenada (G2). Para la toma de 
muestras se seleccionaron productores ( $\mathrm{G} 1$ : $\mathrm{n}=19, \mathrm{G} 2: \mathrm{n}=21$ ) en función de la facilidad de acceso hasta la UPA y en cada visita se realizó un proceso de capacitación en buenas prácticas de ordeño (BPO).

La colecta de muestras se realizó en dos periodos, entre noviembre y diciembre de 2018 y entre enero y febrero de 2019. En cada período, por cada grupo (G1 y G2) y productor se tomaron tres muestras, una de agua, una de la superficie del tarro de leche y una de la leche. Las muestras de agua fueron colectadas de los dispositivos de abastecimiento disponibles (tanques o recipientes de almacenamiento) utilizando frascos de plástico estériles $(500 \mathrm{ml})$ previa homogenización. En caso de encontrar más de un recipiente, una muestra proporcional fue colectada de cada fuente de abastecimiento. Las muestras de superficie y de leche fueron colectadas del tarro donde se almacenaba la leche del ordeño completo. Para la muestra de su- perficie se utilizaron hisopos estériles sumergidos en $10 \mathrm{ml}$ de agua peptonada al $0.1 \%$ enmarcando un área $\left(10 \times 10 \mathrm{~cm}^{2}\right)$ interna de la parte media del recipiente. Una vez terminado el ordeño, la leche fue colectada usando un agitador por 30 segundos y un cucharón de acero inoxidable (previamente esterilizado), y las muestras fueron colectadas en frascos de $40 \mathrm{ml}$ conteniendo azidiol como conservante, de acuerdo con el procedimiento estandarizado para CBT (Agrocalidad, 2017; MAGAP, 2013).

Todas las muestras fueron colectadas durante el segundo ordeño del día, transportadas al laboratorio de la Universidad Politécnica Salesiana en contenedores con hielo $\left(4-7^{\circ} \mathrm{C}\right)$ y analizadas dentro de las 12 horas siguientes.

Los análisis microbiológicos de coliformes totales y fecales en las muestras de agua fueron realizados por filtración por membra-

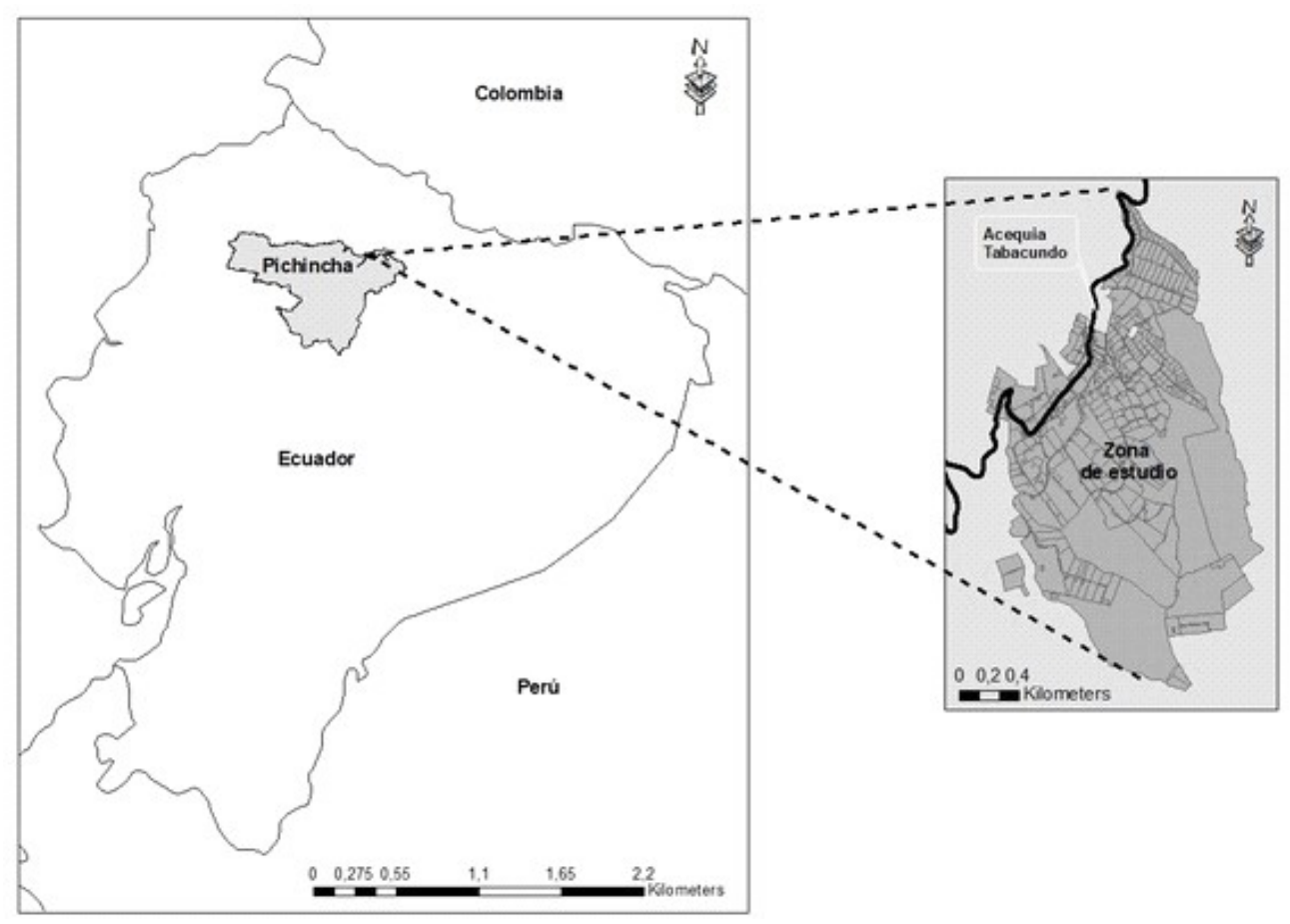

Figura 1. Área de estudio 
na conforme a los requerimientos indicados en normativa APHA (2012). Las diluciones fueron preparadas y sembradas por duplicado en agar cromogénico EcoliBlue e incubadas a $45 \pm 2{ }^{\circ} \mathrm{C}$ por $48 \mathrm{~h}$, y para determinar el resultado e identificación de bacterias fecales fue utilizado un contador de colonias. El análisis de CBT para leche cruda fue determinado por citometría de flujo con uso del equipo BactoScan FC (Foss Analytical), según los procedimientos recomendados (MAGAP, 2013; Numthuam et al., 2017).

Para el análisis de las superficies de los tarros de leche, se evaluaron los mesófilos aerobios utilizando el método del conteo en placa con Agar Estándar (PCA) con diluciones seriadas de $10^{-1}$ a $10^{-5}$ de agua peptonada al $0.1 \%$. Las placas fueron sembradas por duplicado e incubadas a $30 \pm 2^{\circ} \mathrm{C}$ por $48 \mathrm{~h}$. Para los resultados fueron seleccionadas placas con 25 a 250 colonias respetado el área muestreada y expresando los resultados en $\mathrm{UFC} / 100 \mathrm{~cm}^{2}$ (Vázquez, 2007).

\section{Análisis de Datos}

Se realizó una estadística descriptiva de los datos. Para el análisis de correlación se transformó a logaritmo de base 10 los datos de las variables coliformes del agua y CBT de la leche de los grupos G1 y G2. Se utilizó la prueba de T de Student para los datos de la variable CBT. Los resultados de mesófilos aerobios de los tarros de leche fueron analizados mediante la prueba de Chi cuadrado comparando el cumplimiento del límite para «limpieza aceptable» $\left(<400 \mathrm{UFC} / \mathrm{cm}^{2}\right)$ según la norma NOM-093-SSA1-1994 para superficies inertes.

\section{Resultados}

La población en estudio estuvo integrada principalmente por productores entre $24 \mathrm{y}$ 59 años $(71 \%)$ y entre 60 y 85 años (29\%).
El nivel educativo del $79.4 \%$ era menor de seis años de escolaridad. que corresponde a un nivel básico elemental. Para el sustento económico de la familia, los productores combinaban otras actividades agrícolas con la ganadería, donde la producción de leche representaba en promedio el $31 \%$ de los ingresos de familiares, mientras que para el $6.3 \%$ de los productores era la única fuente de ingresos.

El $93.7 \%$ de los productores utiliza ordeño manual y el terreno para el ordeño es compartido por un núcleo familiar o rentado para mantener el ganado. En estos casos, el 98\% de los productores no disponía de agua potable. Para las actividades del ordeño, $48.6 \%$ de los productores transportaban agua potable en recipientes (G1) y $51.4 \%$ utilizaban el agua colectada de otras fuentes almacenadas en el mismo sitio (G2).

La calidad del agua del G1 indica el cumplimiento de los límites permisibles para coliformes totales y fecales, y el valor promedio de CBT correspondió a aquellos de leche de buena calidad $\left(<200 \times 10^{3} \mathrm{UFC} / \mathrm{ml}\right)$. Para el G2, el 29\% de las muestras de agua presentaron coliformes fecales y el valor promedio de CBT en la leche superó el límite permisible. En el G1 10.5\% $(n=2)$ de las muestras presentaron CBT con $800 \times 10^{3} \mathrm{UFC} /$ $\mathrm{ml}$ en tanto que en el G2 19\% ( $\mathrm{n}=4)$ de las muestras presentaron CBT superiores a este valor y el análisis estadístico evidenció diferencia significativa entre los grupos $(\mathrm{p}<0.05)$ (Cuadro 1). La correlación de Pearson entre las variables de coliformes totales y CBT no presentó correlación significativa en ninguno de los grupos.

El análisis microbiológico de la superficie de los tarros de leche mostró superficies limpias $\left(<400 \times 10^{3} \mathrm{UFC} / \mathrm{cm}^{2}\right)$ y contaminadas $\left(>400 \times 10^{3} \mathrm{UFC} / \mathrm{cm}^{2}\right)$ en ambos grupos, sin mostrar diferencia significativa entre estos (Figura 1). 
Cuadro 1. Medias y error estándar (SE) de la calidad microbiológica del agua y leche en ganaderías de productores que utilizan agua potable (G1) o agua de lluvia o de riego (G2) durante el ordeño (Pichincha, Ecuador)

\begin{tabular}{|c|c|c|c|c|c|c|c|c|}
\hline \multirow{3}{*}{ Tipo de agua } & \multirow{3}{*}{$\begin{array}{l}\text { Muestra } \\
\text { (n) }\end{array}$} & \multicolumn{4}{|c|}{ Agua } & \multicolumn{3}{|c|}{ Leche } \\
\hline & & \multicolumn{2}{|c|}{$\begin{array}{c}\text { Coliformes } \\
\text { totales (NMP/100 } \\
\mathrm{ml})^{1}\end{array}$} & \multicolumn{2}{|c|}{ Coliformes fecales } & \multicolumn{3}{|c|}{$\mathrm{CBT}\left(\mathrm{UFC} \times 10^{3} / \mathrm{ml}\right)$} \\
\hline & & Media & $\mathrm{SE}$ & $\begin{array}{l}\text { Presencia/ } \\
\text { Ausencia }^{2}\end{array}$ & $(\%)$ & Media & $\mathrm{SE}$ & $\mathrm{p}<0.05$ \\
\hline \multirow[t]{2}{*}{ Potable (G1) } & 19.0 & 14 & 2 & Ausencia & 100 & 149 & 47.0 & $*$ \\
\hline & & & & Presencia & - & & & \\
\hline \multirow{2}{*}{$\begin{array}{l}\text { De otras } \\
\text { fuentes (G2) }\end{array}$} & 210 & 1281 & 347 & Ausencia & 71 & 906 & 622 & \\
\hline & 21.0 & 1201 & 341 & Presencia & 29 & & & \\
\hline
\end{tabular}

* diferencia significativa

1 NMP: Número más probable por cada $100 \mathrm{ml}$ de muestra

2 Norma INEN 1108 (2014)

\section{Discusión}

Entre los factores sociales, ambientales y económicos que influyen en la disponibilidad de agua de calidad en los sitios de ordeño en el Ecuador se encuentra la Ley de Reforma Agraria y Colonización de 1964, que al parcelar y distribuir los terrenos entre las comunidades en 2-3 sectores, se distanció el lugar de la vivienda ubicada en los centros poblados y con acceso a agua potable, de las unidades productivas ubicadas en zonas altas montañosas que tienen únicamente acceso a agua de riego (Martínez, 2016). Otros factores son el avance de la frontera agrícola por la destrucción de los ecosistemas generadores de agua como páramos y bosques andinos (Hidalgo, 2010), el uso excesivo de fertilizantes inorgánicos, biosidas y vehículos de tracción mecánica que, aunque incrementan la productividad de los suelos también afectan negativamente a los ecosistemas (Vinueza, 2015).

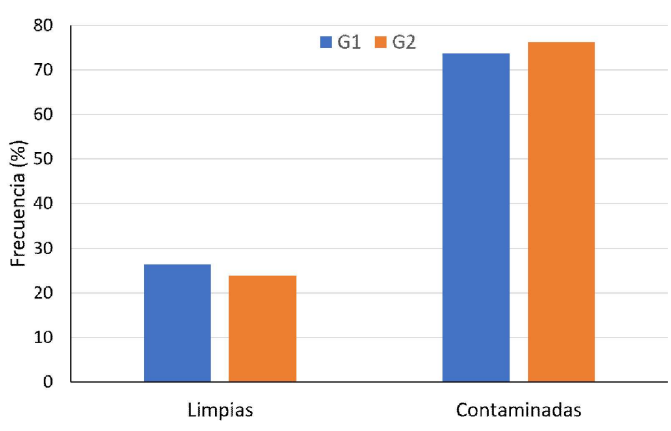

Figura 2. Niveles de contaminación (mesófilos aerobios, UFC/100 $\mathrm{cm}^{2}$ ) en las superficies de tarros de leche en ganaderías que utilizan agua potable (G1) y agua de lluvia o de riego (G2) durante el ordeño (Pichincha, Ecuador)

El déficit del recurso obliga a utilizar agua de riego para suplir las necesidades cotidianas en la producción de leche. Varios estudios han demostrado una correlación significativa entre la calidad microbiana del agua 
de riego y la contaminación por indicadores fecales (Perkins et al., 2009; Henao-Herreño et al., 2017). La mala calidad bacteriológica del agua también puede causar problemas digestivos en los animales, en tanto que la presencia de productos químicos y patógenos en el agua puede originar la ocurrencia de diversas enfermedades en el ganado (PerezMercado et al., 2018; Gallegos y Medina, 2019).

Para Perkins et al. (2009), la prevalencia de $E$. coli en el agua utilizada para el lavado de equipos de ordeño se asocia significativamente con recuentos elevados de bacterias en la leche en tanques de expansión, en el cual el contenido bacteriano puede provenir de fuentes como de la ubre incluyendo pezones, así como de los materiales utilizados, sugiriendo que la limpieza debe realizarse con un suministro de agua potable. Otros trabajos también señalan preocupación por la calidad del agua utilizada en el ordeño, como los estudios de Rangel et al. (2015) en Rio Grande del Norte, Brasil, que informaron valores para coliformes totales y fecales de $5520 \mathrm{UFC} / 100 \mathrm{ml}$ y $3483 \mathrm{UFC} / 100 \mathrm{ml}$, respectivamente; y Amenu et al. (2016) en explotaciones del sur de Etiopía quienes advirtieron la presencia de E. coli en $39.2 \%$ de las muestras de agua.

Las BPO recomiendan el lavado de manos y brazos del personal (utilizando agua y jabón) previo el ordeño (FAO, 2011; Belage et al., 2017), pero los productores en este estudio no disponían de agua potable y transportaban agua en 1-2 recipientes plásticos $(4.0$ L); sin embargo, el volumen no era suficiente para el cumplimiento adecuado de las actividades de ordeño. Además, el $63.5 \%$ de las personas que realizaban el ordeño era mujeres y $14 \%$ de ellas eran mayores de 60 años, por tanto, transportar mayor cantidad de agua no sería una opción viable. Resultados similares en cuanto a la población dedicada a actividades pecuarias fueron reportados por Vinueza (2015), donde 51.4\% eran mujeres.
El resultado promedio de CBT fue de $717 \times 10^{3} \mathrm{UFC} / \mathrm{ml}$, mayor al reportado en propiedades con ordeño manual en el sudoeste de Goiania con 290x 10 ${ }^{3} \mathrm{UFC} / \mathrm{ml}$ (Silva et al., 2010), pero similar a los reportados por Bruzaroski et al. (2017) en el estado de Paraná, ambos en Brasil. Según Martin et al. (2019), los factores ambientales inciden sobre los niveles de esporas bacterianas encontradas en la leche. En el presente estudio se detectó que $75 \%$ de los tarros colectores presentaron superficies con una limpieza inapropiada $\left(>400 \mathrm{UFC} / \mathrm{cm}^{2}\right)$; además, las dificultades climáticas (polvo o lluvia) durante el ordeño realizado a «campo abierto» en áreas sin cubierta como techo son factores que podrían generar ambientes propicios para el crecimiento de bacterias.

Se espera que los tarros deben ser lavados con agua y jabón inmediatamente después de entregar la leche, y que sean revisados antes del ordeño para confirmar la eliminación de residuos y malos olores (FAO, 2011; Cortezi, 2014; Cortinhas et al., 2018). El centro de acopio de leche conoce del déficit de agua de buena calidad en el sitio de ordeño, por lo que dispone de espacios y agua caliente para lavar los tarros en sus instalaciones después de la entrega de la leche, siendo posibles factores de contaminación, un lavado incorrecto y el tiempo que transcurre hasta el próximo ordeño.

\section{Conclusiones}

- En las unidades productivas agropecuarias (UPA) de la provincia de Pichincha, Ecuador, el ordeño manual se realiza bajo condiciones que no permiten disponer de agua libre de contaminantes bacterianos y fecales.

- La limpieza de los materiales, lavado de manos y ubres de las vacas se lleva a cabo con agua que no cumple con los límites de calidad microbiológica. 
- Los tarros colectores de leche presentan contaminación mostrando fallas en los procedimientos de limpieza y desinfección. En general, la calidad del agua incide en la calidad microbiológica de la leche.

\section{Literatura Citada}

1. Agrocalidad. 2017. Resolución 028 . Programa de certificación, seguimiento y recertificación de unidades de producción en Buenas Prácticas Agropecuarias a nivel nacional. [Internet]. Disponible en: https://www.gob.ec/

2. Amenu K, Shitu D, Abera M. 2016. Microbial contamination of water intended for milk container washing in smallholder dairy farming and milk retailing houses in southern Ethiopia. Springerplus 5(1): 1195. doi: 10.1186/ s40064-016-2841-x

3. Amaral LA, Romano APM, Filho AN, Júnior ODR. 2004. Qualidade da água em propriedades leiteiras como fator de risco à qualidade do leite e à saúde da glândula mamária. Arq Inst Biol 71: 417-421.

4. [APHA] American Public Health Association. 2012. Standard methods for the examination of water and wastewater. $22^{\text {th }}$ ed. APHA. $724 \mathrm{p}$.

5. Belage E, Dufour S, Bauman $C$, Jones-Bitton A, Kelton DF. 2017. The Canadian National Dairy Study 2015 Adoption of milking practices in Canadian dairy herds. J Dairy Sci 100: 38393849. doi: $10.3168 /$ jds.2016-12187

6. Botaro BG, Gameiro AH, Santos MV dos. 2013. Quality based payment program and milk quality in dairy cooperatives of Southern Brazil: an econometric analysis. Sci Agric 70: 21-26. Sci Agric doi: 10.1590/S0103-90162013000100004

7. Bruzaroski SR, Trento I, Rezente S, Pereira F, Botaro B, Santos J, Ludovico A, Santana E. 2017. Legal standards of milk delivered for proces- sing in Brazil. Biosci J 33: 364-370. doi: 10.14393/BJ-v33n2-34114

8. Carloni E, Petruzzelli A, Amagliani G, Brandi G, Caverni F, Mangili $P$, Tonucci $F$. 2016. Effect of farm characteristics and practices on hygienic quality of ovine raw milk used for artisan cheese production in central Italy. Anim Sci J 87: 591-599. doi: 10.1111/asj.12452

9. Caro-Hernández PA, Tobar JA. 2019. Análisis microbiológico de superficies en contacto con alimentos. Entramado 16: 240-249. doi: 10.18041/1900-3803/entramado.1.6126

10. Cassoli L, Machado P, Rodrigues A, Coldebella A. 2007. Correlation study between standard plate count and flow cytometry for determination of raw milk total bacterial count Int J Dairy Technol 60: 44-48. doi: 10.1111/j.1471-0307.2007.00297.x

11. Comunidad Europea. 2006. Reglamento $(C E) N^{\circ} 1662 / 2006$. Normas específicas de higiene de los alimentos de origen animal. [Internet]. Disponible en http://data.europa.eu/eli/reg/2006/1662/oj

12. Contero R. 2018. Capacitação técnica em boas práticas de ordenha e ocorrência de patógenos causadores de mastites contagiosas em propriedades leiteiras do estado de São Paulo. Tesis de Doutor. Brasil: Universidade de São Paulo. 107 p.

13. Cortezi AM. 2014. Condições higiênicosanitárias e de manejo e rebanhos lieteros correlacionados á qualidade do leite cru refrigerado. Tesis de Mestre. Brasil: Universidad Estadual Paulista. 68 p.

14. Cortinhas CS, Botaro BG, de Macedo SN, Dos Santos MV. 2018. Herd characteristics and management practices associated with bulk tank milk quality of dairy herds in Southeastern Brazil. Trop Anim Health Pro 50: 1605-1610. doi: 10.1007/s11250-018-1601-z

15. FAO. 2011. Buenas prácticas de ordeño. Guatemala: FAO. 20 p.

16. Gallegos JP, Medina X. 2019. Determinación de pesticidas y calidad de agua de efluentes de florícolas en la zona de 
Cayambe. Tesis de Ingeniero Ambiental. Quito, Ecuador: Univ. Politécnica Salesiana. 52 p.

17. Guamán RA, Masaquiza MD, Curbelo L. 2017. Caracterización de sistemas productivos lecheros en condiciones de montaña, Parroquia Químiag, Provincia Chimborazo, Ecuador. Rev Prod Anim 29: 14-24.

18. Guerra MG, Galvão JGB, Do Nascimento AH, De Araújo VM, Guilhermino MM, Novaes LP. 2011. Disponibilidade e qualidade da água na produção de leite. Acta Vet Bras 5: 230-235.

19. Henao-Herreño LX, López-Tamayo AM, Ramos-Bonilla JP, Haas CN, Husserl J. 2016. Risk of illness with Salmonella due to consumption of raw unwashed vegetables irrigated with water from the Bogotá River. Risk Anal 37: 733-743. doi: 10.1111/risa.12656

20. Hidalgo J. 2010. Dinámica de acumulación de derechos de agua y conflictos. Estudio de caso de la acequia Tabacundo, Ecuador. Tesis de Maestría. Países Bajos: Wagenigen University. $108 \mathrm{p}$.

21. [INEC] Instituto Nacional de Estadísticas y Censos. 2019. Encuesta de superficie y producción Agropecuaria Continua (ESPAC) 2018. INEC. [Internet]. Disponible en: https://www.ecuadorencifras.gob.ec > espac-2018

22. [INEN] Instituto Ecuatoriano de Normalización. 2014. Agua Potable. Requisitos. [Internet]. Disponible en: https:/ /archive.org/details/ec.nte.1108.2011

23. Jansen W, Müller A, Grabowski NT, Kehrenberg $C$, Muylkens $B, A l$ Dahouk S. 2019. Foodborne diseases do not respect borders: zoonotic pathogens and antimicrobial resistant bacteria in food products of animal origin illegally imported into the European Union. Vet J 244: 75-82. doi: 10.1016/j.tvj1.2018.12.009

24. [MAGAP] Ministerio de Agricultura, Ganadería y Acuacultura y Pesca. 2013. Resolución DAJ 2013461-
0201.02014. [Internet]. Disponible en: https://www.oficial.ec/resolucion-0016reformese-resolucion-no-daj-201346102010213-21-noviembre-2013

25. Martin NH, Kent DJ, Evanowski RL, Zuber Hrobuchak TJ, Wiedmann M. 2019. Bacterial spore levels in bulk tank raw milk are influenced by environmental and cow hygiene factors. J Dairy Sci 102: 9689-9701. doi: 10.3168/jds.201916304

26. Martínez L. 2016. Territorios campesinos y reforma agraria: el caso de las cooperativas indígenas de la sierra ecuatoriana. Mundo Agrario 17: 19.

27. NOM-093-SSA1-1994. Bienes y servicios. Prácticas de higiene y sanidad en la preparación de alimentos que se ofrecen en establecimientos fijos. Norma mexicana [Internet]. Disponible en: http:/ /www.dof.gob.mx/nota_detalle.php?codigo $=4721115 \&$ fecha $=29 / 07 / 1994$

28. Numthuam S, Hongpathong J, Charoensook R, Rungchang S. 2017. Method development for the analysis of total bacterial count in raw milk using near-infrared spectroscopy. J Food Saf 37: e12335. doi: 10.1111/jfs. 12335

29. [OECD] Organisation for Economic Co-operation and Development. 2016. Water, growth and finance. Polity perspectives. OECD, better policies for better lives. [Internet]. Disponible en: https://www.oecd.org/environment/ resources/Water-Growth-and-Financepolicy-perspectives.pdf

30. Perez-Mercado LF, Lalander C, Joel A, Ottoson J, Iriarte M, Oporto C, Vinnerås B. 2018. Pathogens in crop production systems irrigated with lowquality water in Bolivia. J Water Health 16: 980-990. doi: 10.2166/wh.2018.079

31. Perkins NR, Kelton DF, Hand KJ, MacNaughton G, Berke O, Leslie KE. 2009. An analysis of the relationship between bulk tank milk quality and wash water quality on dairy farms in Ontario, 
Canada. J Dairy Sci 92: 3714-2722. doi: 10.3168/jds.2009-2030

32. Poats SV, Zapatta A, Cachipuendo $C$. 2001. Estudio de caso: la acequia Tabacundo y las microcuencas de los ríos Pisque y la Chimba en los Cantones Cayambe y Pedro Moncayo, Provincia del Pichincha, en el Norte del Ecuador. [Internet]. Disponible en: https:// www.yumpu.com/es/document/read/ 51962368/la-acequia-tabacundo-mecanismo-de-informacian-de-paramos

33. Ramírez-Rivera EJ, Rodríguez-Miranda J, Huerta-Mora IR, CárdenasCágal A, Juárez-Barrientos JM. 2019. Tropical milk production systems and milk quality: a review. Trop Anim Health Pro 51: 1295-1305. doi: 10.1007/s11250-01901922-1

34. Rangel A, Freire R, Borba L, Junior $D$, Novaes LP. 2015. Qualidade microbiológica da água utilizada em propriedades leiteiras. Rev Inst Laticínios Cândido Tostes 70: 9-16. doi: 10.14295/ 2238-6416.v6970i1.356

35. Silva E, Murillo C, Nava G, Peralta A, Paredez M. 2010. Estudio de caracterización de la calidad microbiológica y fisicoquímica del agua utilizada en la industria de alimentos, Colombia. Biomédica 30: 421-431.

36. Silva M, Santos P, Silva J, Leão K, Oliveira A, Nicolau E. 2010. Variação da qualidade do leite cru refrigerado em função do período do ano e do tipo de ordenha. Rev Inst Adolfo Lutz 69: 112118.

37. Urresta LR, García JR, Noval-Artíles E, Quilismal R, Vargas-Hernandez, $S$. 2017. Contenido mineral en suelo y pastos en rebaños bovinos lecheros de la región andina de Ecuador. Cen Agric 44: 56-64.

38. Vázquez DI. 2007. Evaluación de metodologías de control higiénico de superficies alimentarias y adaptación de la PCR en tiempo real como método de control de patógeno. Tesis Doctoral. Barcelona, España: Univ. Autónoma de Barcelona. 183 p.

39. Vinueza G 2015. Evaluación de las escuela de la revolución agraria (Eras's) en el fomento de la agricultura sostenible en la provincia de Imbabura. Tesis de Maestría. Ecuador: Univ. de las Fuerzas Armadas del Ecuador. $150 \mathrm{p}$. 